УДК 539.214

\title{
Structural-Phase Conditions and Flow Stress at Plastic Deformation of Steel 12X18H10T
}

\author{
Aidyn E. Tussupzhanov*a,b,c, \\ Dosym Yerbolatuly ${ }^{\mathrm{b}}$ and Liudmila I. Kveglis ${ }^{\mathrm{b}, \mathrm{c}}$ \\ ${ }^{a}$ Nazarbayev Intellectual School, Department of Physics \\ 53 Kanysh Satpayev, Ust-Kamenogorsk, 070000, Kazakhstan \\ ${ }^{b}$ S. Amanzholov East Kazakhstan State University \\ 3430 Gvardeiskoi Divisii Str., Ust-Kamenogorsk, 070002, Kazakhstan \\ 'Siberian Federal University \\ 79 Svobodny, Krasnoyarsk, 660041, Russia
}

Received 19.12.2018, received in revised form 11.03.2019, accepted 22.05.2019

The article presents the results of structural and phase transformations and their correlation with microhardness in steel 12 X18H10T after thermomechanical treatment and high-temperature plastic deformation. Assessments of the true flow stress during high-temperature uniaxial tension.

Keywords: plastic deformation, structural and phase state, stainless steel, martensite.

Citation: Tussupzhanov A.E., Yerbolatuly D., Kveglis L.I. Structural-phase conditions and flow stress at plastic deformation of steel 12X18H10T, J. Sib. Fed. Univ. Eng. technol., 2019, 12(4), 438-448. DOI: 10.17516/1999-494X-0150.

(c) Siberian Federal University. All rights reserved

This work is licensed under a Creative Commons Attribution-NonCommercial 4.0 International License (CC BY-NC 4.0).

* Corresponding author E-mail address: aidyn.tussupzhanov@mail.ru, e_dosym@mail.ru 


\title{
Структурно-фазовые состояния и напряжение течения при пластической деформации стали 12X18Н10Т
}

\author{
А.Е. Тусупжанов ${ }^{\mathrm{a}, \tilde{\sigma}, \mathrm{p}}$, Д. Ерболатулы ${ }^{\tilde{\sigma}}$, Л.И. Квеглис ${ }^{\tilde{0}, \mathrm{~B}}$ \\ ${ }^{a}$ Назарбаев Интеллектуальные школь, МО физики \\ Казахстан, 070000, Усть-Каменогорск, пр. К. Сатпаева, 53 \\ ${ }^{\circ}$ Восточно-Казахстанский государственный университет \\ имени С. Аманжолова \\ Казахстан, 070002, Усть-Каменогорск, ул. 30 Гвардейской дивизии, 34 \\ ${ }^{6}$ Сибирский федеральный университет \\ Россия, 660041, Красноярск, пр. Свободныгй, 79
}

В статье представлены результаты структурно-фазовых превращений и их корреляции c микротвердостью в стали $12 X 18 H 10 T$ после термомеханической обработки и высокотемпературной пластической деформации. Сделаны оценки истинных напряжений при одноосном растяжении.

Ключевые слова: пластическая деформация, структурно-фазовое состояние, нержавеющая сталь, мартенсит.

\section{Введение}

Как известно, сталь 12Х18Н10Т широко используется в промышленности как коррозионностойкий и износоустойчивый материал. Этот матераил применяется в ядерном реакторостроении [1-3].

Пластичность, обусловленная мартенситным $\gamma \rightarrow \alpha^{\prime}$-превращением, аустенитных сталей при низких температурах описана в работе [4]. Это превращение влияет на величину деформационного упрочнения и локализацию течения материала. Интенсивность образования мартенсита зависит от степени термической стабильности исходной $\gamma$-фазы (аустенита) и от термомеханической обработки. Старение и подбор оптимальной температуры приводит к более быстрому $\gamma \rightarrow \alpha^{\prime}$-превращению [4]. Можно предположить, что большая доля мартенсита способна увеличить степень деформации при высокотемпературной деформации сталей. Ранее нами была изучена сверхпластичность превращения с $\mathrm{Co}-\mathrm{Ni}-\mathrm{Nb}$ сплава в работах $[5,6]$. В работе [5] описана наша методика для определения истинных напряжений. Эта методика была апробирована на сплавах, где при высокотемпературной деформации происходит фазовое превращение.

В данной работе исследуются структурно-фазовое состояние и высокотемператураная деформация стали 12X18Н10T, обладающие уникальными физическими свойствами. Цель работы - исследовать структурно-фазовое состояние стали до и после пластической деформации при высоких температурах [7].

\section{Материалы и методы исследования}

Сталь 12Х18Н10Т применяется в качестве коррозионностойкого и жаропрочного материала и имеет следующий химический состав: основа $\mathrm{Fe}, 0,12 \%-\mathrm{C}, 18 \%-\mathrm{Ni}, 10 \%-\mathrm{Ti}$. Термическая обработка стали производилась в муфельной печи СОУЛ-4 с использованием кварцевой труб-

$$
-439-
$$


ки, где создавался вакуум не менее $10^{-3}$ МПа. Закалку проводили в воде комнатной температуры. Прокатку стали осуществляли на прокатном стане стандартного изготовления. Высокотемпературная пластическая деформация стали проводилась в испытательной машине 1246Р, где создавался вакуум не менее $10^{-5}$ МПа. Исследование микроструктуры проводили на оптическом микроскопе Неофот-21 и сканирующем электронном микроскопе JSM-6390LV производства компании JEOL Ltd. (Япония) с системой энергодисперсионного микроанализа INCA Energy Penta FET X3 компании OXFORD Instruments Analytical Limited. Фазовый состав образцов исследовали на рентгеновском дифрактометре ДРОН-3 с гониометрической приставкой ГП-13 с применением кобальтового и медного излучения, а также на мессбауеровском спектрометре MC1104ЕM с ${ }^{57} \mathrm{Co-источником} \mathrm{гамма-кванттов.}$

\section{Результаты и их обсуждение}

Для исследования эволюции структурно-фазовых превращений после термомеханической обработки и высокотемпературной пластической деформации нами была изучена структура стали после прокатки и отжига. В исходном состоянии структура стали имеет множество двойников, размер зерен составляет $\langle d\rangle=19$ мкм (рис. $1 a$ ). После прокатки на $80 \%$ микроструктура стали плохо выявляется, наблюдается лишь деформационный рельеф в виде волокон текстуры вдоль одного направления (рис. 1б). При низкотемпературном отжиге прокатанной стали не отсутствуют рекристаллизационные процессы, структура является волокнистой с темными участками (рис. 18). Дальнейшее увеличение температуры обработки приводит к образованию темных участков. Это области обратного мартенситно-аустенитного превращения, о чем свидетельствуют данные рентгеноструктурного анализа (рис. 3в). В отличие от низкотем-
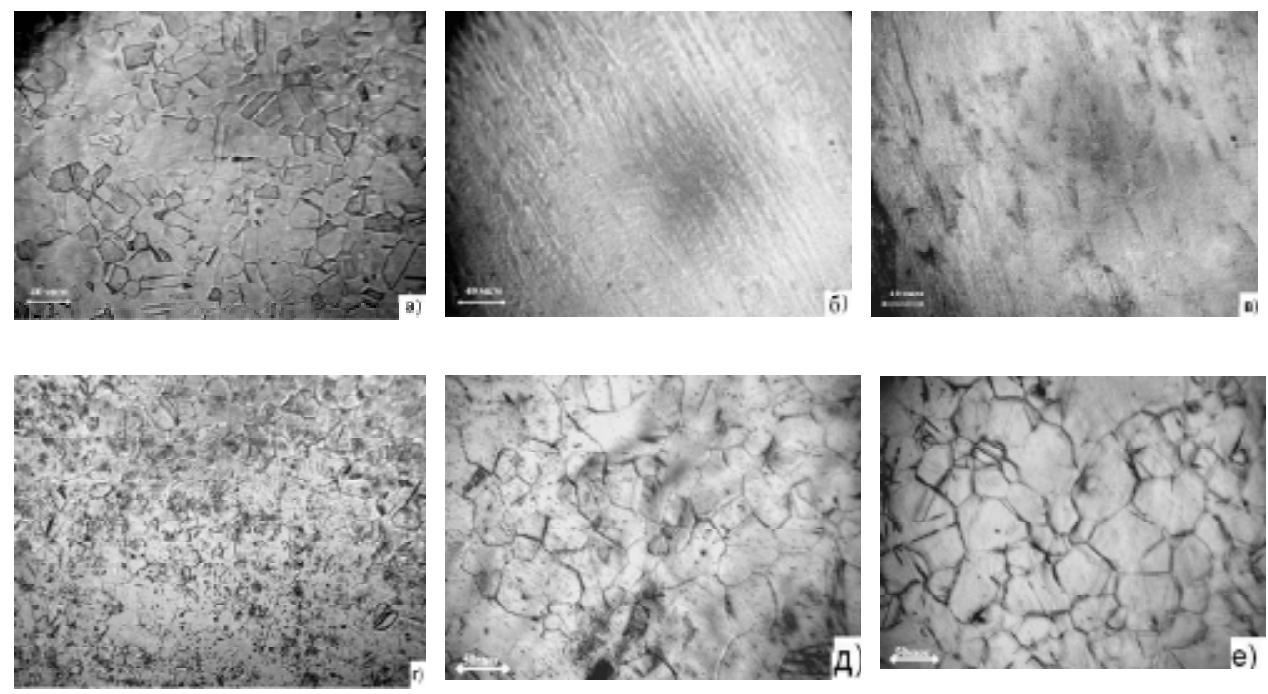

Рис. 1. Микроструктура стали 12Х18Н10T: а) исходное состояние; б) прокатка на 80 \%; в) прокатка на $80 \%+$ отжиг при $600{ }^{\circ} \mathrm{C}\left(30\right.$ мин); г) прокатка на $80 \%+$ отжиг при $920{ }^{\circ} \mathrm{C}(30$ мин); д) прокатка на $80 \%$ + отжиг при $1000{ }^{\circ} \mathrm{C}\left(30\right.$ мин); е) прокатка на $80 \%$ + отжиг при $1200{ }^{\circ} \mathrm{C}(30$ мин)

Fig. 1. The microstructure of steel $12 \mathrm{Cr} 18 \mathrm{Ni10Ti}$ a) initial condition; б) $80 \%$ rolling; в) rolling for $80 \%+$ annealing at $600{ }^{\circ} \mathrm{C}(30 \mathrm{~min})$; г) rolling at $80 \%+$ annealing at $920{ }^{\circ} \mathrm{C}(30 \mathrm{~min})$; д) rolling at $80 \%+$ annealing at $1000{ }^{\circ} \mathrm{C}(30 \mathrm{~min}) ;$ e) rolling at $80 \%+$ annealing at $1200^{\circ} \mathrm{C}(30 \mathrm{~min})$ 
пературного отжига при температурах выше $920{ }^{\circ} \mathrm{C}$ микроструктура стали выявлена в виде рекристаллизованных зерен (рис. $12, \partial$, e) и рентгенограммы (рис. $32, \partial$, e) соответственно. По фотографиям микроструктуры (рис. $1 \partial, e$ ) стали видно, что при высоких температурах отжига выше $1000{ }^{\circ} \mathrm{C}$ происходит рост зерен аустенита. Так, при $1000{ }^{\circ} \mathrm{C}$ средний размер зерен $\langle d\rangle=37,3$ мкм, $1100{ }^{\circ} \mathrm{C}-\langle d\rangle=35,3$ мкм, $1200{ }^{\circ} \mathrm{C}-\langle d\rangle=45,8$ мкм (рис. $1 \partial, e$ ).

Также нами проведены микроструктурные исследования на растровом электронном микроскопе с приставкой для энергодисперсионного анализа «INCA Energy». Как видно на рис. $2 a$, особого различия между химическими составами не наблюдается, что косвенно подтверждает образование мартенсита деформации при прокатке стали, поскольку мартенсит образуется бездиффузионным методом [8]. После отжига при $920{ }^{\circ} \mathrm{C}$ также отсутствуют изменения в химическом составе (рис. 2б).

Рентгенодифракционные исследования образцов стали в исходном и отожженных состояниях приведены на рис. 3. Сначала сталь находится в $\gamma$-аустенитном состоянии (рис. $3 a$ ) с ГЦКрешеткой с параметром решетки а $=3,59 \AA$. А после прокатки на $80 \%$ сталь полностью переходит в $\alpha^{\prime}-$-жезе с параметром решетки $\alpha_{\alpha}=2,875 \AA$ (рис. 36 ) [9]. Мартенситные превращения $\gamma$-Fe в $\alpha^{\prime}$-фазу происходят в условиях пластической деформации, которые связаны с избыточными объемами в локальных наномасштабных областях $[10,11]$.

На дифрактограмме образцов после отжига при $600{ }^{\circ} \mathrm{C}$ наблюдается появление линий $\gamma$-Fe (аустенита), а также изменение соотношения интенсивностей линий $\alpha^{\prime}$-фазы (рис. 36 ), свиде-
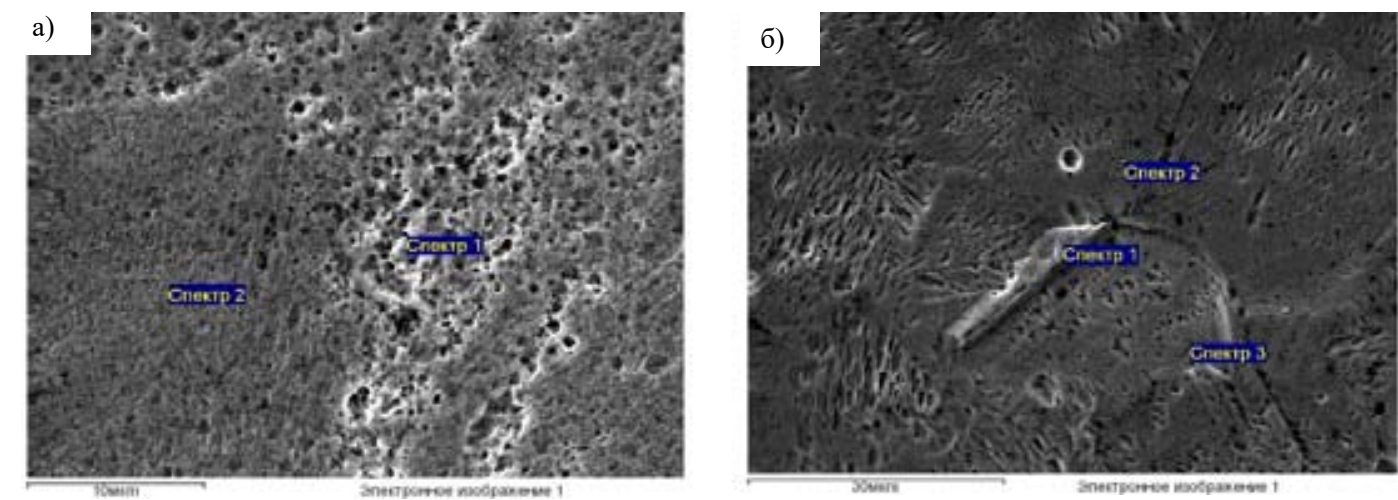

\begin{tabular}{|l|l|l|l|l|l|l|l|}
\hline Спектр & В стат. & $\mathrm{Si}$ & $\mathrm{Cr}$ & $\mathrm{Mn}$ & $\mathrm{Fe}$ & $\mathrm{Ni}$ & Итог \\
\hline & & & & & & & \\
\hline Спектр 1 & Да & 0.40 & 19.69 & & 71.94 & 7.97 & 100.00 \\
\hline Спектр 2 & Да & 0.53 & 18.94 & 1.34 & 71.45 & 7.74 & 100.00 \\
\hline Спектр 3 & Да & 0.43 & 19.72 & & 72.02 & 7.83 & 100.00 \\
\hline & & & & & & & \\
\hline Макс. & & 0.53 & 19.72 & 1.34 & 72.02 & 7.97 & \\
\hline Мин. & & 0.40 & 18.94 & 1.34 & 71.45 & 7.74 & \\
\hline
\end{tabular}

\begin{tabular}{|l|l|l|l|l|l|l|l|}
\hline Спектр & В стат. & $\mathrm{Si}$ & $\mathrm{Cr}$ & $\mathrm{Mn}$ & $\mathrm{Fe}$ & $\mathrm{Ni}$ & Итог \\
\hline & & & & & & & \\
\hline Спектр 1 & Да & & 19.22 & 0.93 & 71.63 & 8.22 & 100.00 \\
\hline Спектр 2 & Да & 0.46 & 18.85 & 1.26 & 71.61 & 7.82 & 100.00 \\
\hline & & & & & & & \\
\hline Макс. & & 0.46 & 19.22 & 1.26 & 71.63 & 8.22 & \\
\hline Мин. & & 0.46 & 18.85 & 0.93 & 71.61 & 7.82 & \\
\hline
\end{tabular}

Рис. 2. Микроструктура и микроанализ стали $12 \mathrm{X} 18 \mathrm{H} 10 \mathrm{~T}$ : а) прокатка на $80 \%$ + отжиг при $600{ }^{\circ} \mathrm{C}$; б) прокатка на $80 \%$ + отжиг при $920^{\circ} \mathrm{C}$

Fig. 2. Microstructure and Microanalysis of steel $12 \mathrm{Cr} 18 \mathrm{Ni10Ti}$ a) rolling at $80 \%+$ annealing at $600{ }^{\circ} \mathrm{C}$; б) rolling at $80 \%+$ annealing at $920{ }^{\circ} \mathrm{C}$ 


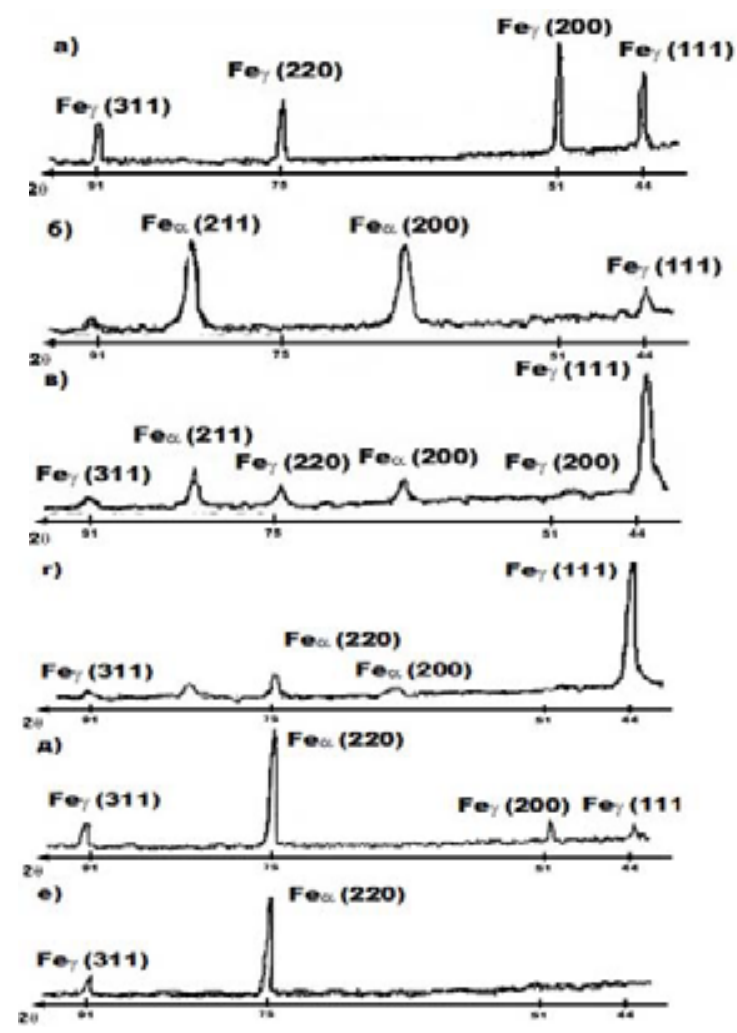

Рис. 3. Фрагменты дифрактограмм стали 12Х18H10Т: а) исходное состояние; б) прокатка на $80 \%$; в) прокатка на $80 \%+$ отжиг при $600{ }^{\circ} \mathrm{C}\left(30\right.$ мин); г) прокатка на $80 \%+$ отжиг при $920{ }^{\circ} \mathrm{C}(30$ мин); д) прокатка на $80 \%+$ отжиг при $1000{ }^{\circ} \mathrm{C}\left(30\right.$ мин); е) прокатка на $80 \%$ + отжиг при $1200{ }^{\circ} \mathrm{C}(30$ мин)

Fig. 3. Fragments of diffractograms of steel 12Cr18Ni10Ti: a) initial condition; б) $80 \%$ rolling; в) rolling for $80 \%$ + annealing at $600{ }^{\circ} \mathrm{C}(30 \mathrm{~min}) ;$ г) rolling at $80 \%+$ annealing at $920{ }^{\circ} \mathrm{C}(30 \mathrm{~min})$; д) rolling at $80 \%+$ annealing at $1000{ }^{\circ} \mathrm{C}(30 \mathrm{~min})$; e) rolling at $80 \%+$ annealing at $1200{ }^{\circ} \mathrm{C}(30 \mathrm{~min})$

тельствующие о снятии внутренних напряжений при отжиге. Отжиг при 700-800 ${ }^{\circ} \mathrm{C}$ не вызвал значительных фазовых изменений. Лишь линии $\gamma$-Fe (аустенита) стали более выраженными. Важным экспериментальным данным является то, что в данной работе установлен верхний температурный предел перехода $\alpha^{\prime}$-фазы в $\gamma$-Fe для образцов, предварительно прокатанных на $80 \%,-920{ }^{\circ} \mathrm{C}$ (рис. 32). Дальнейшее увеличение температуры отжига приводит лишь к росту интенсивности пиков от $\gamma$-Fe (рис. 3d). Также установлено, что повышение температуры отжига стали вызывает увеличение параметров решетки аустенита и мартенсита, так, после отжига при $700{ }^{\circ} \mathrm{C}$ параметры решеток $\alpha_{\alpha}=2,878 \AA, \alpha_{\gamma}=3,6 \AA$.

Повышение температуры отжига приводит к резкому увеличению среднего размера зерна, что отрицательно влияет на эксплуатационные свойства стали. На рис. 4 представлены изменения микротвердости после различных обработок. В исходном состоянии микротвердость стали равна $\mathrm{H}=2507$ МПа. После прокатки происходит увеличение микротвердости до $\mathrm{H}=5372$ МПа из-за образования мартенсита деформации (рис. 36). При обработке прокатки на $80 \%$ и отжиге при $600{ }^{\circ} \mathrm{C}$ наблюдается уменьшение микротвердости до $\mathrm{H}=4566$ МПа. Дальнейшее увеличение температуры отжига приводит к постепенному уменьшению микро- 
твердости, так, при температуре отжига $920{ }^{\circ} \mathrm{C}$ микротвердость образца равна $\mathrm{H}=1883$ МПа (рис. 4).

Исследования фазового состава на мессбауеровском спектрометре МC1104ЕМ с ${ }^{57} \mathrm{Co}-$ источником гамма-квантов подтверждают результаты, полученные ранее. Как показано на рис. $5 a$, в исходном состояниии сталь находится в аустенитном состоянии, как известно, ау-

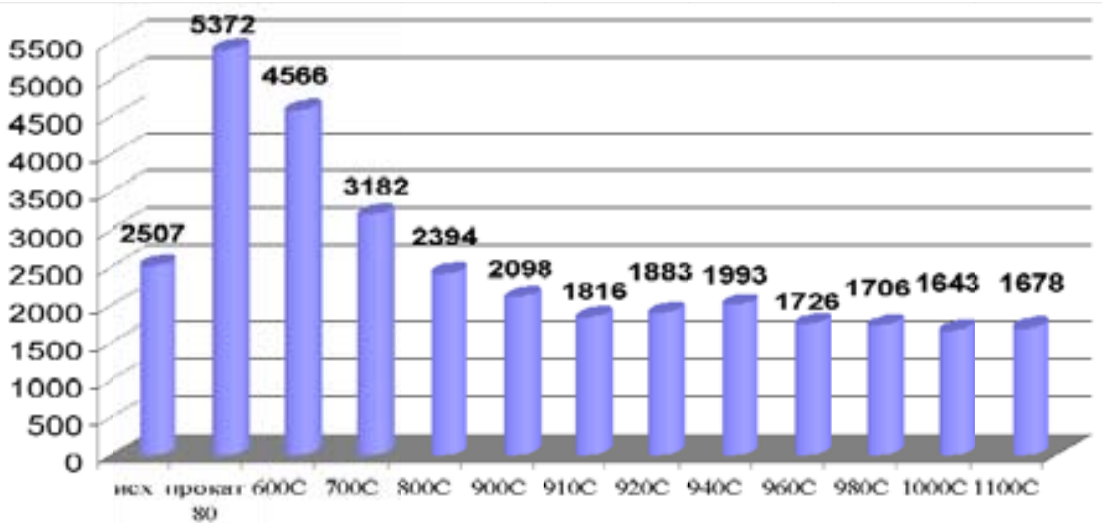

Рис. 4. Микротвердость стали 12Х18Н10Т после различных обработок

Fig. 4. Microhardness of steel 12Cr18Ni10Ti after various treatments
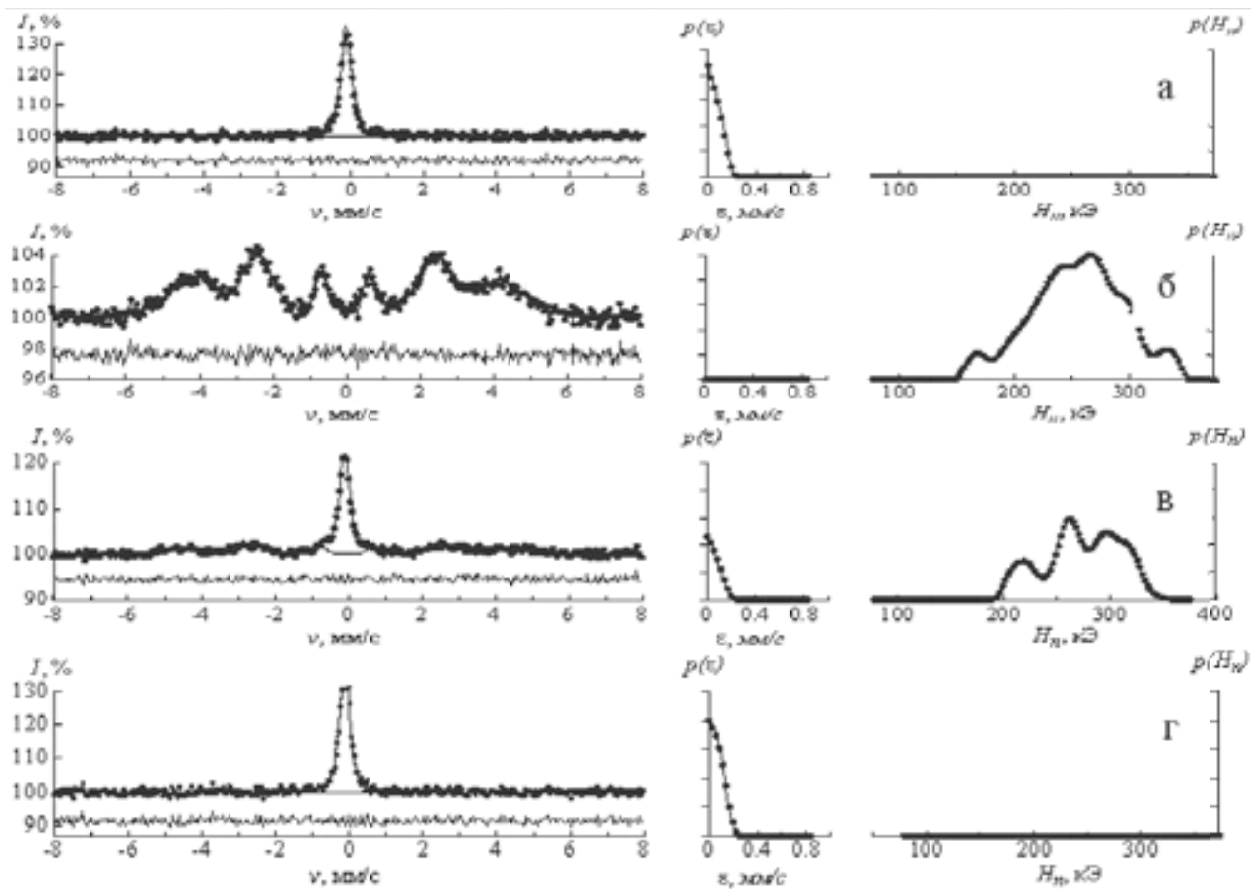

Рис. 5. Мессбауеровские спектры стали 12Х18Н10Т: а) исходное состояние; б) прокатка на 80 \%; в) прокатка на $80 \%$ + отжиг при $600{ }^{\circ} \mathrm{C}\left(30\right.$ мин); г) прокатка на $80 \%$ + отжиг при $1000{ }^{\circ} \mathrm{C}(30$ мин)

Fig. 5. Mössbauer spectra of steel $12 \mathrm{Cr} 18 \mathrm{Ni10Ti}$ a) initial condition; б) $80 \%$ rolling; в) rolling for $80 \%+$ annealing at $\left.600{ }^{\circ} \mathrm{C}(30 \mathrm{~min}) ; \mathrm{r}\right)$ rolling at $80 \%+$ annealing at $1000{ }^{\circ} \mathrm{C}(30 \mathrm{~min})$ 
стенит является немагнитной фазой. У прокатанных на 80 \% образцов стали мессбауеровские спектры отличаются от исходных (рис. $5 a, 6$ ). В исходном состоянии наблюдается один пик, а в прокатанном - секстед. У оттоженных при $600{ }^{\circ} \mathrm{C}$ образцов стали наблюдаются пики как от аустенита, так и от мартенсита, также у образца сохраняются магнитные свойства. С повышением температуры отжига стали исчезают магнитные свойства и пики от мартенсита (рис. 5d). Данные, полученные методом гамма-резонансной спектроскопии, подтверждают данные, полученные методом рентгено-дифракционного фазового анализа.

Спектр обработан методом восстановления распределения сверхтонкого магнитного поля и методом модельной расшифровки. Видно, что максимум восстановленного распределения сверхтонкого магнитного поля достигается при $\mathrm{H}_{\mathrm{n}} \sim 280 \mathrm{k}$, после обработки прокатки на 80 \% (рис. 5б). Это связано с перераспределением электронной плотности вокруг ядра железа. Такое перераспределение возникает благодаря формированию новой фазы - мартенсита деформации. После отжига при $600{ }^{\circ} \mathrm{C}$ максимум восстановленного распределения сверхтонкого магнитного поля смещается, $\mathrm{H}_{\mathrm{n}} \sim 260 \mathrm{k}$ Э (рис. 58). Это свидетельствует о неполном превращении ферромагнитного мартенсита в парамагнитный аустенит [12].

Поскольку в исследуемой стали не образовывается фаза диффузионным методом, то высокотемпературная пластичность происходит только за счет зернограничного проскальзывания. Поэтому структура стали после высокотемпературной деформации является высокопористой (рис. $6 a$ ). В стали также наблюдается вязкое разрушение (рис. 6б) [13]. Показатель пластичности $\delta=130 \%$.

Рентгенофазовый анализ до и после высокотемпературной деформации стали 12X18H10T подтверждает, что образования фаз не происходит (рис. 7), а также то, что при деформации случается обратное превращение мартенсита в аустенит (рис. 7д). Установлено, что высокотемпературная деформация инициирует переход $\alpha$-железа в $\gamma$-железо и снижает температуру перехода с 920 до $780^{\circ} \mathrm{C}$.

На рис. 8 представлены изменения микротвердости стали до и после высокотемпературной деформации. На гистограммах видим, что после проведения прокатки и у стали про-
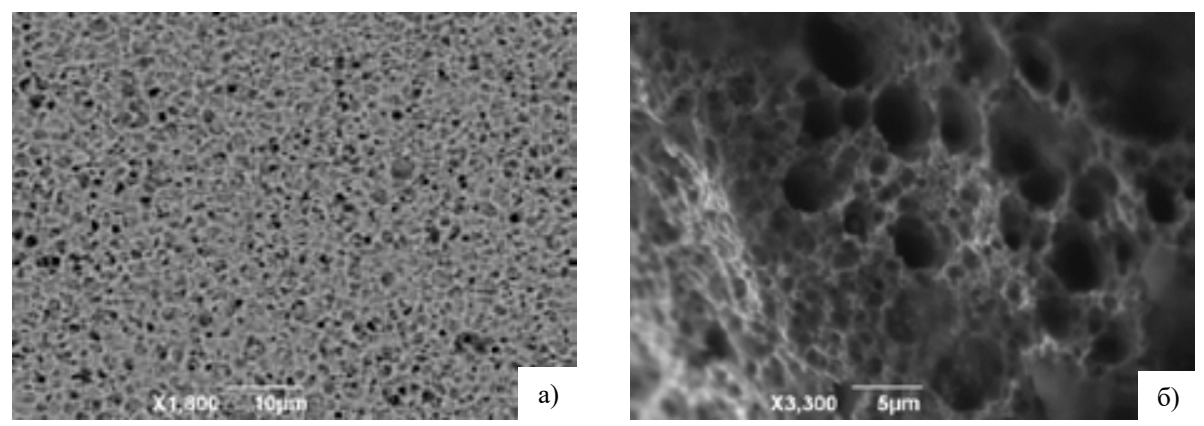

Рис. 6. Микроструктура стали $12 \mathrm{X} 18 \mathrm{H} 10 \mathrm{~T}$ : а) прокатка на $80 \%+$ скоростной нагрев да $820{ }^{\circ} \mathrm{C}(3$ мин $)+$ СПД $\left(\mathrm{T}=780^{\circ} \mathrm{C}, \varepsilon=0,72 \cdot 10^{-2} \mathrm{c}^{-1}\right) ;$ б) поверхность разрушения после СПД на $190 \%$

Fig. 6. The microstructure of steel $12 \mathrm{Cr} 18 \mathrm{Ni10Ti}$ a) rolling at $80 \%+$ high-speed heating and $820{ }^{\circ} \mathrm{C}(3 \mathrm{~min})+$ $\operatorname{SPD}\left(\mathrm{T}=780^{\circ} \mathrm{C}, \varepsilon=0,72 \cdot 10^{-2} \mathrm{c}^{-1}\right) ;$ б) surface damage after SPD by $190 \%$ 


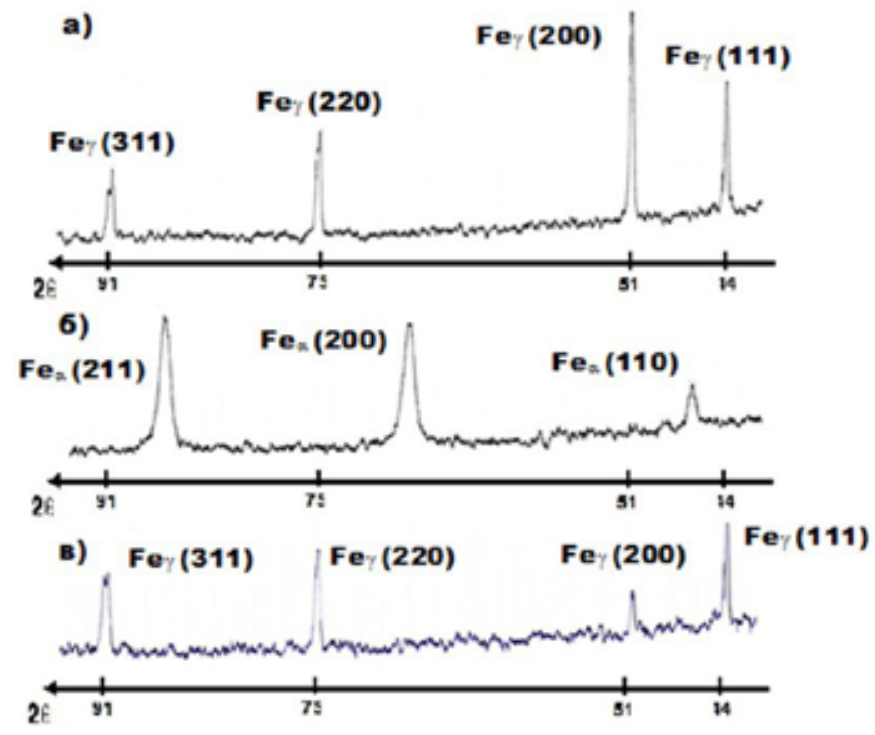

Рис. 7. Фрагменты дифрактограмм до и после высокотемпературной деформации стали 12Х18Н10Т: a) исходный; б) прокатка на $80 \%$; в) прокатка на $80 \%+$ скоростной нагрев до $820{ }^{\circ} \mathrm{C}(3$ мин) + СПД $\left(\mathrm{T}=780^{\circ} \mathrm{C}, \varepsilon=0,72 \cdot 10^{-2} \mathrm{c}^{-1}\right)$

Fig. 7. Fragments of diffraction patterns before and after high-temperature deformation of steel $12 \mathrm{Cr} 18 \mathrm{Ni}$ 10Ti: a) source; б) $80 \%$ rolling; в) rolling at $80 \%+$ high-speed heating to $820{ }^{\circ} \mathrm{C}(3 \mathrm{~min})+\operatorname{SPD}\left(\mathrm{T}=780{ }^{\circ} \mathrm{C}\right.$, $\left.\varepsilon=0,72 \cdot 10^{-2} \mathrm{c}^{-1}\right)$

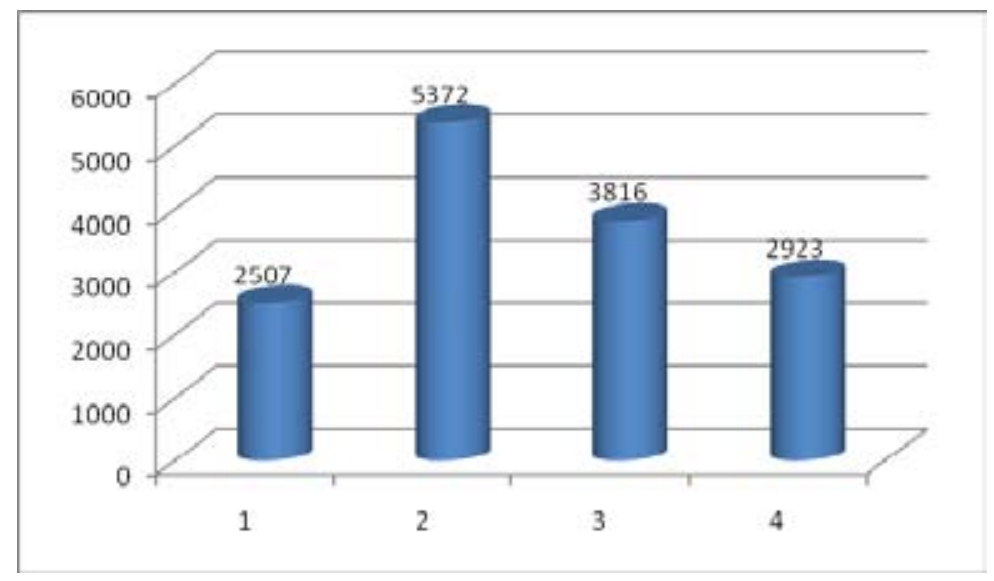

Рис. 8. Изменение микротвердости: 1 - исходный; 2 - прокатка на $80 \%$; 3 - прокатка на $80 \%$ + скоростной нагрев $820{ }^{\circ} \mathrm{C}$ (3 мин); 4 - прокатка на $80 \%+$ скоростной нагрев $820{ }^{\circ} \mathrm{C}(3$ мин $)+\mathrm{CПД}\left(\mathrm{T}=780{ }^{\circ} \mathrm{C}\right.$, $\left.\varepsilon=0,72 \cdot 10^{-3} \mathrm{c}^{-1}\right)$

Fig. 8. Microhardness change: 1 - source; 2 - rolling at $80 \% ; 3$ - rolling at $80 \%$ + high-speed heating $820^{\circ} \mathrm{C}$ $(3 \mathrm{~min}) ; 4$ - rolling at $80 \%+$ high-speed heating $820^{\circ} \mathrm{C}(3 \mathrm{MIN})+\mathrm{SPD}\left(\mathrm{T}=780{ }^{\circ} \mathrm{C}, \varepsilon=0,72 \cdot 10^{-3} \mathrm{c}^{-1}\right)$

исходит увеличение микротвердости в два раза. При проведении деформации уменьшается микротвердость, но значение микротвердости не ниже исходного.

Согласно работам [7, 14], известны два основных типа сверхпластичности: микрозеренная и сверхпластичность превращения. Микрозеренная сверхпластичность свойственна металлам

$$
-445-
$$




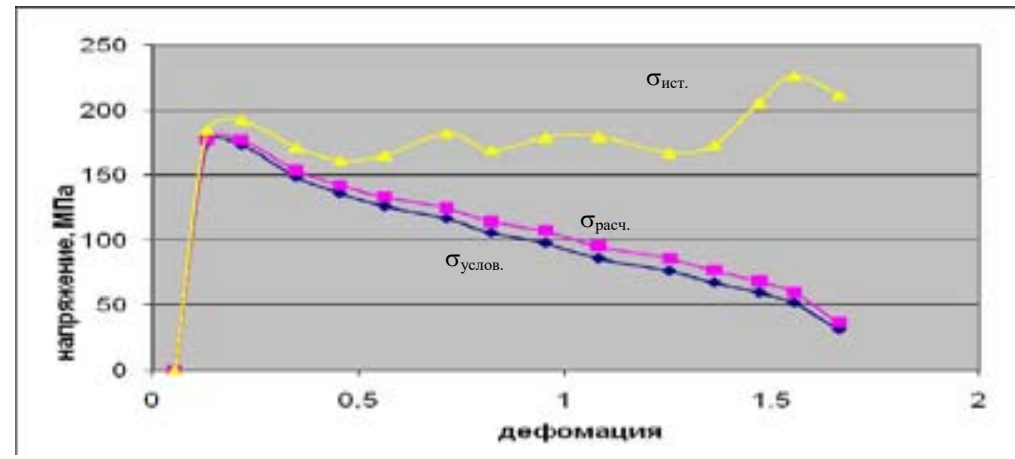

Рис. 9. График изменения напряжения течения в стали $12 \mathrm{X} 18 \mathrm{H} 10 \mathrm{~T}$

Fig. 9. The graph of flow stress in steel $12 \mathrm{Cr} 18 \mathrm{Ni10 \textrm {Ti }}$

и сплавам с очень мелким равноосным зерном. Второй тип - сверхпластичность превращения, проявляется во время фазового превращения. В момент фазового превращения структура резко меняется, образующаяся фаза в начальный момент мелкозернистая, а в период трансформации однофазный сплав становится двухфазным.

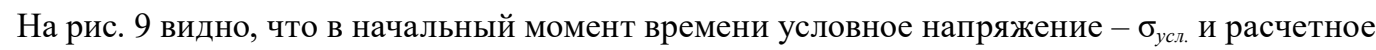
теоретическое напряжение - $\sigma_{\text {раси }}$ растет и, достигая предела прочности, равномерно уменьшается. А истинное напряжение $\sigma_{u c m}$, определенное фотометодом, изменяется скачкообразно. В работах [15-17] изложены некоторые особенности исследования истинных напряжений в сталях и сплавах. Истинное напряжение неплохо сходится с теоретическим и условным напряжениями до степени деформации - 0,5 , в дальнейшем происходит рост истинного напряжения, максимум которого достигается в месте разрыва образца. В полученных данных имеется расхождение теоретических данных с экспериментальными, по-видимому, из-за того, что теоретическая формула не учитывает изменения скорости деформации и изменения площади поперечного сечения образца.

\section{Выводы}

Исследованиями структурных и магнитных характеристик установлено, что в результате прокатки происходит образование новой фазы - мартенсита деформации.

Неравновесные мартенситные фазы, возникающие при переходе $\gamma$-Fe в $\alpha^{\prime}$-фазу в условиях пластической деформации, связаны с имеющимися в материале избыточными объемами в локальных наномасштабных областях.

Пластическая деформация в стали 12X18Н10T - высокотемпературная пластическая деформация за счет перехода $\alpha^{\prime}$-фазы в $\gamma$-Fе по типу сверхпластичности превращения.

\section{Список литературы}

[1] Гуляев А.П. Сверхпластичность стали. М.: Металлургия, 1982. 56 с. [Gulyaev A.P. Steel superplasticity. Moscov: Metallurgy, 1982. 56 p. (in Russian)]

[2] Солонин М.И., Кондратьев В.П., Вотинов С.Н. Сплав ХНМ-1 как перспективный материал для элементов конструкции ядерных и термоядерных реакторов с водным теплоноси-

$$
-446-
$$


телем. ВАНТ, Серия Материаловедение и новые материаль, 1995, 1(52), 13-20. [Solonin M.I., Kondratyev V.P., Votinov S.N. Alloy CrNiMg-1 as a promising material for the structural elements of nuclear and thermonuclear reactors with a water-cooled medium. VANT, Series Materials Science and New Materials, 1995, 1(52), 13-20 (in Russian)]

[3] Колотушкин В.И., Влияние структурного состояния на стабильность Cr-Ni сталей и сплавов при облучении нейтронами. ФМM, 2004, 97(2), 63-73. [Kolotushkin V.I. Influence of the structural state on the stability of Cr-Ni steels and alloys under neutron irradiation, FMM, 2004, 97(2), 63-73 (in Russian)]

[4] Новиков И.И. Теория термической обработки металлов. М.: Металлургия, 1978 [Novikov I.I. Theory of heat treatment of metals. M., Metallurgy, 1978 (in Russian)]

[5] Тусупжанова А.Е., Ерболатулы Д., Квеглис Л.И., Немцев И.В. Исследование напряжения течения при сверхпластической деформации $\mathrm{Co}-\mathrm{Ni}-\mathrm{Nb}$ сплава. Журнал Сибирского федерального университета. Техника и технологии, 2015, 8(6), 802-810 [Tussupzhanov A.E., Yerbolatuly D., Kveglis L.I., Nemcev I.V. The Study of the Flow Stress During Superplastic Deformation Co-Ni-Nb Alloy. Journal of Siberian Federal University. Engineering \& Technologies, 2015, 8(6), 802-810 (in Russian)]

[6] Тусупжанова А.Е., Ерболатулы Д., Квеглис Л.И., Филяровский А. Исследование структурно-фазовых состояний и особенностей пластической деформации аустенитного твердосплавного сплава Co-Ni-Nb. Металль 2018, 8(1), 19; doi:10.3390/met8010019 [Tussupzhanov A.E., Yerbolatuly D., Kveglis L.I. and Filarowski A. Investigation of Structural-Phase States and Features of Plastic Deformation of the Austenitic Precipitation-Hardening Co-Ni-Nb Alloy. Metals 2018, 8(1), 19; doi:10.3390/met8010019 (in Russian)]

[7] Новиков И.И., Золоторевский В.С., Портной В.К., Белов Н.А., Ливанов Д.В., Медведева С.В., Аксенов А.А., Евсеев Ю.В. Металловедение. Т. І. М.: Издательский Дом МИСиС, 2009. 496 c. [Novikov I.I., Zolotorevsky V.S., Portnoy V.K., Belov N.A., Livanov D.V., Medvedeva S.V., Aksenov A.A., Evseev Yu.V. Metal science. Vol. I. M.: Publishing House MISiS, 2009. 496 p. (in Russian)]

[8] Смирнов М.А., Счастливцев В.М., Журавлев Л.Г. Основы термической обработки сталей. Екатеринбург: Институт физики металлов УрО РАН, 1999. 496 с. [Smirnov M.А., Schastlivtsev V.M., Zhuravlev L.G. Fundamentals of heat treatment of steels Ekaterinburg: Institute of Metal Physics, Ural Branch of the Russian Academy of Sciences, 1999. 496 p. (in Russian)]

[9] Горелик С.С., Скаков Ю.А., Расторгуев Л.Н. Рентгенографический и электроннооптический анализ. М.: МИСИС, 2002. 360 с. [Gorelik S.S., Skakov Yu.A., Rastorguev L.N. Radiographic and electron-optical analysis. M.: MISIS, 2002. 360 p. (in Russian)]

[10] Панин В.Е., Панин А.В., Почивалов Ю.И., Елсукова Т.Ф., Шугуров А.Р. Масштабная инвариантность структурных трансформаций при пластической деформации наноструктурных твердых тел. Физ. мезомеханика, 2017, 20(1), 57-71 [Panin V.E., Panin A.V., Pochivalov Yu.I., Elsukova T.F., Shugurov A.R. Scale invariance of structural transformations under plastic deformation of nanostructured solids. Fiz. Mesomechanics, 2017, 20(1), 57-71 (in Russian)]

[11] Панин В.Е., Егорушкин В.Е., Елсукова Т.Ф. и др. Многомасштабное трансляиионновращательное пластическое течение в поликристаллах. Справочник по механике материалов. Под ред. С.-Х. Hsuch et. и др. Сингапур: Springer Nature Singapore Pte Ltd., 2018. [Panin V.E.,

$$
-447-
$$


Egorushkin V.E., Elsukova T.F. et al. Multiscale Translation-Rotation Plastic Flow in Polycrystals. Handbook of Mechanicd of Materials. Ed. By C.-H. Hsuch et. al. Singapore: Springer Nature Singapore Pte Ltd., 2018 (in Russian)]

[12] Кэмпбелл С.И., Качмарек В.А. Мессбауэровская спектроскопия применительно к материалам и магнетизму. Под ред. G.J. Лонг, Ф. Гранджин. Н.Ю., Пленум Пресс, 1996. Т. 2. [Campbell S.I., Kaczmarek W.A. Mossbauer spectroscopy applied to materials and magnetism. Ed. G.J. Long, F. Grandjean. N.Y. Plenum Press, 1996. Vol. 2. (in Russian)]

[13] Гоулдстейн Дж., Ньюбери Д., Джой Д., Фиори Ч., Лифшин Э. Растровая электронная микроскопия и рентгеновский микроанализ: В 2 кн. Книга 2. Пер. с англ. М.: Мир, 1984. 348 c. [Goldstein J., Newbury D., Joy D., Fiori Ch., Lifshin E. Plant electron microscopy and X-ray microanalysis: In 2 books. Book 2. Trans. from English. Moscow: Mir, 1984. 348 p. (in Russian)]

[14] Као Ф.Р., Ли Ж.Л., Чжан Н.Х., Дин, Х., Йю F.Х., Зуо Л., Сверхпластичность, течение и механизм разрушения в сплаве $\mathrm{Al}-12,7 \mathrm{Si}-0,7 \mathrm{Mg}$. Материаловедение и инженерия. А 2013, 167-183 [Cao F.R., Li Z.L., Zhang N.X., Ding H., Yu F.X., Zuo L., Superplasticity, flow and fracture mechanism in an Al-12.7Si-0.7Mg alloy. Mater. Sci. Eng. A 2013, 167-183 (in Russian)]

[15] Хорита 3., Фурукава М., Немото М., Барнерс А.Дж, Лэнгдон Т.Г. Сверхпластическое формирование при высоких скоростях деформации после сильной пластической деформации. Acta. Mater. 2000, 48, 3633-3640. [Horita Z., Furukawa M., Nemoto M., Barnes A.J., Langdon T.G. Superplastic forming at high strain rates after severe plastic deformation. Acta. Mater. 2000, 48, 3633 3640. (in Russian)]

[16] Смолей А., Клобзар Д., Сказа Б., Наголе А., Слацек Е., Драгоевич В., Смолей С., Сверхпластичность прокатанного и обработанного трением сплава $\mathrm{Al}-4,5 \mathrm{Mg}-0,35 \mathrm{Sc}-0,15 \mathrm{Zr}$. Maтериаловедение и инженерия А 2014, 590, 239-245. [Smolej A., Klobčar D., Skaza B., Nagode A., Slaček E., Dragojević V., Smolej S., Superplasticity of the rolled and friction stir processed Al-4.5 Mg-0.35Sc-0.15Zr alloy. Mater. Sci. Eng. A 2014, 590, 239-245 (in Russian)]

[17] Ли С., Уцуномия А, Акамацу Х., Неиши К., Фурукава М., Хорита З., Лэнгдон Т.Г. Влияние скандия и циркония на стабильность зерна и сверхпластичные пластичности в ультрамелкозернистых сплавах Al - Mg. Acta. Mater. 2002, 50, 553-564 [Lee S., Utsunomiya A., Akamatsu H., Neishi K., Furukawa M., Horita Z., Langdon T.G. Influence of scandium and zirconium on grain stability and superplastic ductilities in ultrafine-grained Al-Mg alloys. Acta. Mater. 2002, 50, 553-564 (in Russian)] 